\title{
PEDAGOGIA HISTÓRICO-CRÍTICA E PEDADOGIA DA LIBERTAÇÃO: APROXIMAÇÕES E DISTANCIAMENTOS
}

\author{
PEDAGOGÍA HISTÓRICO-CRÍTICA Y PEDADOGÍA DE LA LIBERACIÓN: \\ APROXIMACIÓNS Y DISTANCIAMIENTOS
}

\section{HISTORICAL-CRITICAL PEDAGOGY AND PEDAGOGY OF LIBERATION: APPROXIMATIONS AND DISTANCES}

\author{
DOI: https://doi.org/10.9771/gmed.v13i3.47177
}

\section{Dermeval Saviani ${ }^{i}$}

Resumo: Este artigo trata da relação entre a pedagogia histórico-crítica e a pedagogia de Paulo Freire mostrando, num primeiro momento, suas convergências na medida em que ambas se colocam na perspectiva dos interesses da maioria da população constituída pela classe dos trabalhadores tendo em vista a articulação da educação com a transformação estrutural da sociedade capitalista. No segundo momento são abordadas as diferenças entre as duas pedagogias tomando como referência a fundamentação filosófica e as formulações pedagógicas.

Palavras-chave: Pedagogia libertadora. Pedagogia histórico-crítica. Paulo Freire.

Resumen: Este artículo aborda la relación entre la pedagogía histórico-crítica y la pedagogía de Paulo Freire, mostrando, en un primer momento, sus convergencias en la medida en que ambas se sitúan en la perspectiva de los intereses de la mayoría de la población constituida por la clase obrera con miras a articulación de la educación con la transformación estructural de la sociedad capitalista. En el segundo momento, se discuten las diferencias entre las dos pedagogías, tomando como referencia el fundamento filosófico y las formulaciones pedagógicas.

Palabras clave: Pedagogía de la liberácion. Pedagogía histórico-crítica. Paulo Freire.

Abstract This article deals with the relationship between the historical-critical pedagogy and Paulo Freire's pedagogy, showing, at first, their convergences insofar as both are placed in the perspective of the interests of the majority of the population constituted by the working class with a view to articulating of education with the structural transformation of capitalist society. In the second moment, the differences between the two pedagogies are discussed, taking as reference the philosophical foundation and the pedagogical formulations.

Keywords: Liberating pedagogy. Historical-critical pedagogy. Paulo Freire

\section{Introdução}

O ano de 2021, no marco dos 100 anos do nascimento de Paulo Freire comemorados em 19 de setembro, foi palco de muitos eventos em homenagem a esse grande educador brasileiro, realizados de forma virtual em razão da pandemia do coronavírus que ainda persiste. Dentre as várias lives de que participei, destacase aquela na qual, considerando que em 2021 também se comemoram os 30 anos do lançamento do livro Pedagogia histórico-crítica: primeiras aproximações (SAVIANI, 1991; 12 $\mathrm{a}$ ed. 2021a), me foi pedido para abordar a relação entre a pedagogia histórico-crítica e a pedagogia freireana indicando suas convergências e diferenças. Germinal: Marxismo e Educação em Debate, Salvador, v. 13, n. 3, p. 170-176, deそ: 2021 ISSN: 2175-5604 170 
Começo, então, por abordar alguns aspectos que indicam a convergência de propósitos entre essas duas concepções pedagógicas, destacando, no segundo momento, os pontos que as colocam em posições distintas.

\section{Aproximações entre a Pedagogia Histórico-Crítica e a Pedagogia de Paulo Freire}

Ambas as pedagogias se colocam na perspectiva dos interesses da maioria da população entendendo a educação como instrumento para libertar os trabalhadores da dominação e opressão a que estão submetidos na sociedade atual. Assim sendo, ambas consideram que cabe à educação conscientizar as camadas populares para torná-las senhoras do próprio destino atuando para transformar a sociedade fazendo valer seus interesses e o atendimento de suas necessidades. Ambas efetuam, então, uma crítica direta à educação dominante denunciando seu papel alienante visando a conformar a população à ordem existente e tornando-a submissa aos interesses dominantes. Em consequência, ambas consideram que a educação é sempre um ato político de tal modo que a defesa de um suposto caráter apolítico, neutro e desinteressado da educação não passa de uma maneira de reforçar a submissão da educação à ordem política dominante. Dessa forma, agir como se a educação fosse isenta de influência política é uma forma eficiente de colocá-la a serviço dos interesses dominantes. Portanto, tanto a pedagogia histórico-crítica como a pedagogia da libertação proposta por Freire assumem que, ao proclamar a neutralidade da educação, o objetivo a atingir é o de estimular o idealismo dos professores fazendo-os acreditar na autonomia da educação em relação à política, o que os fará atingir o resultado inverso ao que estão buscando: em lugar de, como acreditam, estar preparando seus alunos para atuar de forma autônoma e crítica na sociedade, estarão formando para ajustálos melhor à ordem existente e aceitar as condições de dominação às quais estão submetidos. Em consequência, ambas propõem uma educação crítica que forme pessoas autônomas capazes de desenvolver uma prática social transformadora em contraposição à educação acrítica que forma pessoas dependentes e reprodutoras da ordem vigente. Vê-se, assim, que os seguintes princípios da concepção de homem, sociedade e educação esboçada por Freire em seu primeiro trabalho Educação e atualidade brasileira (FREIRE, 1959), tese apresentada ao concurso para a Cadeira de História e Filosofia da Educação da Escola de Belas Artes de Pernambuco, integrante da então Universidade do Recife, que em 1967 se transformou na atual Universidade Federal de Pernambuco, são assumidos também pela pedagogia histórico-crítica:

a) Para ser instrumento de mudança social a educação precisa manter relação orgânica com o contexto da sociedade em que se encontra;

b) Essa relação orgânica implica num conhecimento crítico da realidade para que a educação possa se integrar a ela e não a ela se superpor;

c) Sua superposição à realidade decorrente de transplantes sem a necessária adequação à nova circunstância torna a educação inautêntica e, por isso, inoperante;

d) A emersão do povo precisa ser promovida pela educação à crítica, a qual, fundando-se na razão, não deve significar uma posição racionalista, mas uma abertura do homem pela qual, mais lucidamente, 
possa ver seus problemas. Posição que implica na libertação do homem de suas limitações pela consciência dessas limitações (FREIRE, 1959, p. 122-123).

Do mesmo modo, a pedagogia histórico-crítica também postula "uma educação para a decisão, para a responsabilidade social e política" (FREIRE, 1974, p. 88), que possibilite aos seres humanos "a discussão corajosa de sua problemática" (idem, p. 89) como se posiciona Paulo Freire no terceiro capítulo, "Educação versus massificação", do livro Educação como prática da liberdade.

\section{Distanciamentos entre a Pedagogia Histórico-Crítica e a Pedagogia de Freire}

Vou abordar as diferenças começando pela fundamentação filosófica passando, depois, às formulações pedagógicas.

Do ponto de vista da fundamentação filosófica ambas tomam como referência o ponto mais avançado atingido pela filosofia contemporânea representado pela fenomenologia existencial e pelo marxismo. No entanto, enquanto a pedagogia da libertação se coloca na posição da fenomenologia existencial expressa pelo personalismo cristão a partir do qual incorpora contribuições do marxismo, a pedagogia histórico-crítica assume plenamente o marxismo como concepção integral capaz de dar conta de todos os problemas enfrentados pela humanidade não necessitando, pois, de complementações advindas de outras correntes filosóficas. Tomando como referência as matrizes do pensamento marxista representados por Marx, Engels, Lênin e Gramsci, a Pedagogia Histórico-Crítica empreende a crítica das demais correntes da filosofia contemporânea correspondentes à fenomenologia, existencialismo e filosofia analítica superando suas insuficiências. Já a Pedagogia da Libertação proposta por Freire apresenta-se como a versão pedagógica da Teologia da Libertação que opera uma distinção entre materialismo dialético e materialismo histórico entendendo que o materialismo dialético é doutrina e, como tal, é incompatível com a doutrina da Igreja Católica enquanto o materialismo histórico é ciência e, assim sendo, mostra como ocorreu e vem ocorrendo objetivamente o desenvolvimento histórico da humanidade evidenciando os processos de dominação. Assim, a Teologia da Libertação, para operar de acordo com a "opção preferencial pelos pobres" deve levar em conta os conhecimentos científicos elaborados pelo materialismo histórico mediante os quais o marxismo traz importantes contribuições às lutas de libertação dos povos oprimidos. Eis como Paulo Freire expressou esse posicionamento em resposta à pergunta: "Paulo, tu te definirias como sendo marxista?"

Eu lhes digo que, por respeito a Marx, eu não me defino marxista. Um teórico que aceite algum a priori da História ou na História não é marxista; e eu dizia, ironizando, que este teórico corre o risco de, encontrando-se com Marx em algum pós-vida, ouvir dele, Marx: meu amigo, você estava equivocado a respeito de minha contribuição teórica. Igualmente, se eu aceito Deus como a priori e não admito ouvir perguntas e questões sobre: como é este deus?, como ele age?, ele é homem, é mulher ou é um fluido? ele mora aqui ou acolá?... Se eu não souber explicitar isto historicamente eu não estarei sendo marxista. Mesmo sobre a natureza do Homem, ele não existe como a priori. Ou seja: eu sou Homem porque me fiz e ainda me faço Homem; inexiste algo no meu "ser Homem" que se constitui fora da História. Nós nos fazemos Homens e Mulheres através da experiência. Agora, reflitam comigo, meus amigos, penso que isto (de não aceitar a prioris) não significa que eu desvalorize a 
contribuição de Marx. Ele não é apenas moda. Justamente porque é a análise dele que me permite desmontar criticamente essa concepção neoliberal que está aí, na pósmodernidade (FREIRE. In: SAVIANI, 2010, p. 9-10).

Vê-se, aí, claramente como Paulo Freire, em virtude de sua crença católica, não pode se definir como marxista, o que não o impede de aceitar o marxismo como ciência (materialismo histórico): "é a análise dele que me permite desmontar criticamente essa concepção neoliberal". Em contrapartida, o entendimento da Pedagogia Histórico-Crítica é que não faz sentido essa cisão entre o materialismo dialético e o materialismo histórico. A concepção elaborada por Marx e continuada pelos marxistas articula esses dois aspectos sendo apropriadamente denominada de materialismo histórico-dialético.

Do ponto de vista das formulações pedagógicas assinalo a relação entre educação popular e educação escolar, a questão da sistematização teórica e a relação educador-educando e professor-aluno.

A Pedagogia da Libertação situa-se naquela modalidade "centrada no saber do povo e na autonomia de suas organizações", preconizando "uma educação autônoma e, até certo ponto, à margem da estrutura escolar; e, quando dirigida às escolas propriamente ditas, busca transformá-las em espaços de expressão das ideias populares e de exercício da autonomia popular". Diferentemente, a Pedagogia Histórico-Crítica se pauta pela "centralidade da educação escolar, valorizando o acesso das camadas populares ao conhecimento sistematizado" (SAVIANI, 2021b, p. 414-415).

Vê-se, assim, que a Pedagogia Libertadora proposta por Paulo Freire surgiu no âmbito do movimento da "educação popular" advogando a organização, no seio dos movimentos populares, de uma educação do povo e pelo povo, para o povo e com o povo em contraposição à educação caracterizada como da elite e pela elite, para o povo , mas contra o povo manejando, pois, a categoria "povo" em lugar de "classe". Como observei no livro História das ideias pedagógicas no Brasil (idem, p. 416), tendia-se a conceber a autonomia popular de uma forma dir-se-ia metafísica, cuja validade não dependeria de condições históricopolíticas determinadas, mas seria decorrente de uma virtude intrínseca aos homens do povo; sua fonte primeira residiria numa dimensão transcendente designada por Mounier como "a eminente dignidade" das pessoas unidas numa "comunidade dos destinos" como podemos ler na obra O Personalismo, uma das principais obras filosóficas inspiradoras de Paulo Freire (MOUNIER, 1970, p. 125-159). Tal visão acentuava a autonomia pedagógica dos movimentos populares diante do Estado e da escola postulando que a educação verdadeiramente libertadora dar-se-ia fora do Estado e também da escola, embora quando o PT assumiu o governo de algumas prefeituras a referida concepção tenha se transladado, de alguma forma, para as esferas estatal e escolar.

Essa, digamos, rejeição da forma como o ensino se desenvolvia na educação escolar se manifesta no quarto capítulo "Educação e conscientização" do livro Educação como prática da liberdade quando Freire descreve o método de alfabetização. Com efeito, para a execução do método, Paulo Freire idealizou os Círculos de Cultura, em lugar de escola; nesses círculos atuariam os coordenadores de debates em lugar dos professores; os coordenadores de debates, por sua vez, em lugar de aula discursiva, exercitariam o diálogo com os participantes do grupo; esses participantes ativos do grupo se constituíam como substitutos dos alunos, com sua tradição de passividade; em lugar dos pontos e programas alienados que os professores normalmente 
trabalham com seus alunos, os coordenadores de grupo trabalhariam com os participantes do grupo uma "programação compacta, reduzida e codificada em unidades de aprendizado" (FREIRE, 1974, p. 103, nota 2).

Diferentemente a Pedagogia Histórico-Crítica surge a partir da constatação de que a educação escolar se tornou, na época moderna sob a dominação da burguesia, a forma principal e dominante de educação a partir da qual as demais formas de educação são entendidas. Assim sendo, a escola veio a assumir no campo pedagógico papel equivalente ao capital na esfera econômica, o que me permitiu parafrasear a frase de Marx (1973, p. 236) “o capital é a força econômica da sociedade burguesa que tudo domina", dizendo que a escola, na sociedade atual, é a força pedagógica que tudo domina. Por isso, embora a renda fundiária tenha precedido historicamente ao capital, "não se pode compreender a renda imobiliária sem o capital. Mas podemos compreender o capital sem a renda imobiliária” (idem, ibidem). Continuando a paráfrase, podemos concluir que, embora as formas de educação não-escolar tenham precedido historicamente à forma escolar, a situação que hoje se configura nos coloca diante do fato de que não nos é mais possível compreender a educação sem a escola. Trata-se, em suma, do princípio metodológico também enunciado por Marx (idem, p. 234) e celebrizado na metáfora "a anatomia do homem é a chave da anatomia do macaco": é a partir do mais desenvolvido que se pode compreender o menos desenvolvido e não o contrário. Logo, parafraseando a metáfora, podemos afirmar que a anatomia da escola é a chave da anatomia da educação (SAVIANI, 2021c, p. 154-155).

Quanto à sistematização teórica e à relação educador-educando e professor-aluno para não me alongar vou comentá-las conjuntamente tomando como referência o célebre aforismo enunciado no livro Pedagogia do oprimido: "Ninguém educa ninguém, ninguém se educa a si mesmo, os homens se educam entre si, mediatizados pelo mundo" (FREIRE, 2005, p. 78) . Esse aforismo é uma frase de efeito, bastante atraente. Mas... qual seu conteúdo? Dir-se-ia que se trata de um slogan tal como explicitado por Israel Scheffler no livro A linguagem da educação. Com efeito, no Capítulo II, tratando dos slogans educacionais, Scheffler começa por mostrar a diferença entre eles e as definições; enquanto estas são consideradas esclarecedoras, aqueles são estimulantes, tendo por função unificar as ideias e atitudes dos movimentos educacionais: "exprimem e promovem, ao mesmo tempo, a comunidade de espírito, atraindo novos aderentes e fornecendo confiança e firmeza aos veteranos" (SCHEFFLER, 1974, p.46). Do mesmo modo que os slogans religiosos e políticos, os slogans educacionais resultam de espírito partidário. Diante disso, Scheffler considera "ocioso criticar um slogan por inadequação formal ou por inexatidão na transcrição do uso" (p.46), mas entende haver uma importante analogia entre eles e as definições. Assim, embora os slogans sejam símbolos unificadores de ideias e atitudes, "com o correr do tempo, entretanto, muitas vezes os slogans passam progressivamente a ser interpretados de maneira mais literal, tanto pelos aderentes como pelos críticos dos movimentos que eles representam" (pp.46-47). Por esse caminho, eles tendem a ser considerados "como argumentos ou doutrinas literais, e não mais simplesmente como símbolos unificantes" (p.47).

De fato, Paulo Freire não manifestava maior preocupação com a sistematização teórica. Suas obras contém análises e considerações político-educativas inspiradoras e estimulantes de engajamento numa 
educação em favor dos oprimidos e esfarrapados do mundo. Esse é seu grande mérito. Também em sua atuação como professor prevalecia certo espontaneísmo colocando-se diante dos alunos numa atitude de abertura e disponibilidade para dialogar sobre temas levantados pelos próprios alunos secundarizando a exigência de elaboração de programa e planejamento das aulas. A ideia de que "os homens se educam entre si mediatizados pelo mundo" se traduzia no enunciado da relação entre educador-educando (professoraluno) e educando-educador (aluno-professor), ou seja, no entendimento de que o professor também aprende com o aluno e, pois, o aluno também ensina ao professor. No entanto, sabemos que as novas gerações são educadas pelas gerações anteriores e que há uma responsabilidade dos adultos, representados pelos professores, diante da educação das crianças e jovens. E é isso que a teoria da Pedagogia HistóricoCrítica formulou ao tomar a prática social como ponto de partida e ponto de chegada da educação, esclarecendo que professores e alunos se situam no interior dessa prática social ocupando posições distintas sendo que no ponto de partida o professor detém uma visão sintética da prática social enquanto o aluno se situa numa visão sincrética.

Eis porque Gramsci conferia papel central ao corpo docente entendendo que, na escola, "o nexo instrução-educação só pode ser representado pelo trabalho vivo do professor, pois o professor tem consciência dos contrastes entre o tipo de sociedade e de cultura que ele representa e o tipo de sociedade representado pelos alunos" (GRAMSCI, 1975, p. 1542). Por estar consciente desse contraste entre seu lugar e o lugar do aluno no processo educativo, o professor tem consciência também de que sua tarefa é "acelerar e disciplinar a formação da criança conforme o tipo superior em luta com o tipo inferior" (idem, ibidem). Conclui, então, que com um corpo docente deficiente afrouxa-se a ligação entre instrução e educação e o ensino degenera em mera retórica que exalta a educabilidade do ser humano em contraste com um trabalho escolar esvaziado de qualquer seriedade pedagógica. Concordando com esse entendimento a Pedagogia Histórico-Crítica considera central o papel do professor defendendo a necessidade de uma formação sólida em cursos de longa duração aliada a condições adequadas de trabalho ao corpo docente.

\section{Conclusão}

Em suma, apesar das diferenças, reitero a perspectiva crítico-transformadora que caracteriza tanto a Pedagogia Libertadora como a Pedagogia Histórico-Crítica. E destaco a perda que significou para nosso país a retirada de Paulo Freire de nosso convívio perpetrada pela ditadura civil-militar de 1964. Minha conjectura é que, sem a ditadura, o ano de 1964 poderia se concluir com as Reformas de Base postas em funcionamento e com o Plano Nacional de Alfabetização, coordenado por Paulo Freire, tendo estendido para milhões de brasileiros analfabetos o êxito obtido com as quarenta horas dedicadas aos trezentos camponeses analfabetos em Angicos, no Rio Grande do Norte. E com certeza Paulo Freire teria se integrado plenamente no nosso movimento educacional com contribuições teórico-práticas significativas para o avanço da educação brasileira tanto no campo da educação popular como no âmbito da educação escolar. O exílio nos privou de sua contribuição e acabou privando também os demais países. Com efeito, apesar 
do reconhecimento de sua obra, em especial a Pedagogia do oprimido, no mundo todo, suas ideias pedagógicas não chegaram a se incorporar na organização educativa de nenhum dos países em que sua obra foi difundida, nem mesmo naqueles, como os países lusófonos da África, aos quais prestou assessoria educacional.

\title{
Referências:
}

FREIRE, Paulo. "Educação: preparação para o século XXI (Diálogo com Paulo Freire e Adriano Nogueira). In: SAVIANI, D. Interlocuções pedagógicas. Campinas, Autores Associados, 2010, p. 1-39.

FREIRE, Paulo. Educação e atualidade brasileira. Recife, Universidade Federal de Pernambuco. Tese de concurso para a cadeira de história e filosofia da educação da Escola de Belas Artes, 1959.

FREIRE, Paulo. Educação como prática da liberdade, 4ª ed. Rio de Janeiro, Paz e Terra, 1974.

FREIRE, Paulo. Pedagogia do oprimido, 46ª ed. Rio de Janeiro, Paz e Terra, 2005.

GRAMSCI, Antonio (1975). Quaderni del carcere (edizione critica dell'Istituto Gramsci a cura de Valentino Gerratana), 4 vol. Torino, Einaudi.

MARX, Karl. Contribuição para a crítica da economia política, 2ª ed. Lisboa, Estampa, 1973.

MOUNIER, Emmanuel. O Personalismo, $3^{\text {a }}$ ed. Lisboa, Moraes, 1970.

SAVIANI, Dermeval. Pedagogia histórico-crítica: primeiras aproximações. Campinas, Autores Associados, 1991 (12 ed. 2021a).

SAVIANI, Dermeval. História das ideias pedagógicas no Brasil, 6a ed. Campinas, Autores Associados, 2021b.

SAVIANI, Dermeval. A pedagogia no Brasil: história e teoria, $3^{\mathrm{a}}$ ed. Campinas, Autores Associados, 2021c.

SCHEFFLER, Israel. A linguagem da educação. São Paulo, Saraiva/EDUSP, 1974.

\begin{abstract}
Notas
${ }^{\text {i }}$ Possui graduação em Filosofia pela Pontifícia Universidade Católica de São Paulo (1966) e doutorado em Filosofia da Educação pela Pontifícia Universidade Católica de São Paulo (1971). Em 1986 obteve o título de livre-docente e em 1991 foi aprovado no Concurso de Professor Titular de História da Educação da UNICAMP. Atualmente é pesquisa e desenvolvimento, ensino da Universidade Estadual de Campinas e professor aposentado da Universidade Estadual de Campinas. É Professor Emérito da UNICAMP e Coordenador Geral do Grupo de Estudos e Pesquisas "História, Sociedade e Educação no Brasil" (HISTEDBR).Tem experiência na área de Educação, com ênfase em Filosofia e História da Educação, atuando principalmente nos seguintes temas: educacao brasileira, legislação do ensino e política educacional, história da educação, história da educação brasileira, historiografia e educação, história da escola pública, pedagogia e teorias da educação. Currículo lattes: http://lattes.cnpq.br/2205251281123354 Orcid: https://orcid.org/0000-0002-3148-3055 E-mail: dermevalsaviani@yahoo.com.br
\end{abstract}

